\title{
Chilean Health Professionals’ Attitudes Towards Deafness: A Cross-Sectional Study
}

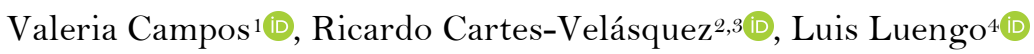

\begin{abstract}
${ }^{1}$ Faculty of Health Sciences, Universidad Autónoma de Chile, Temuco, Chile.
${ }^{2}$ School of Dentistry, Universidad Andrés Bello, Talcahuano, Chile.

${ }^{3}$ F undación Kimntrum, Concepción, Chile.

${ }^{4}$ Department of Public Health and Preventive Dentistry, School of Dentistry, Universidad de Concepción, Concepción, Chile.
\end{abstract}

Author to whom correspondence should be addressed: Valeria Campos, Facultad de Ciencias de la Salud, Universidad Autónoma de Chile, Av. Alemania \#1090, Temuco, Chile. Phone: +56 412204195. E-mail: valeriacamposcannobbio@gmail.com.

Academic Editors: Alessandro Leite Cavalcanti and Wilton Wilney Nascimento Padilha

Received: 12 February 2020 / Accepted: 26 April 2020 / Published: 23 May 2020

How to cite this article: Campos V, Cartes-Velásquez R, Luengo L. Chilean health professionals' attitudes towards
Deafness: a cross-sectional study. Pesqui Bras Odontopediatria Clín Integr. 2020; 20 :e0020.
https://doi.org/10.1590/pboci.2020.087

\begin{abstract}
Objective: To assess the attitudes of health professionals towards Deafness and its association with sociodemographic and Deaf contact experience. Material and Methods: A cross-sectional study was carried out in Concepcion, Chile. The sample size was estimated in 171 health professionals. The following variables were considered: sociodemographics, Deaf contact experience, and attitudes to deafness scale (ADS scale). To evaluate the association between the variables, t-test and Spearman correlation test were used $(\mathrm{p}<0.05)$. Results: People who had taken a LSCh course had significant more positive attitudes towards item 1 "Deaf people should learn to lipread", with a 2 points difference and in persons who do not know a Deaf person, with 1-point difference. Also, persons who have received some kind of formation in Deafness have a better attitude in item 3 "I would like to have more Deaf friends" with 1-point difference. An inverse correlation was observed within age $(r h o=-0.237 ; p=0.0014)$, years of academic service ( $r$ ho = $0.323 ; \mathrm{p}<0.0001)$ or PHC service ( $\mathrm{rho}=-0.1085 ; \mathrm{p}=0,364)$. Conclusion: The attitude of health professionals towards Deafness was neutral. This attitude is not modulated by sex, type of profession, type of relationship with Deaf people, type of training in hearing disability, Chilean Sign Language Courses or degree of frequency of healthcare delivery to Deaf patients. However, it is modulated by age and years of service.
\end{abstract}

Keywords: Hearing Disorders; Deafness; Attitude of Health Personnel; Professional-Patient Relations. 


\section{Introduction}

Most people who are born deaf or have a hearing loss at an early age identify themselves as part of a linguistic minority: The Deaf Community. This community has its own language, customs, values, and, therefore, its own culture: Deaf Culture, and they call themselves "Deaf" with a capital "D". Sign Language (SL), their most significant cultural element, differs from spoken languages at a phonological, syntactic and grammar level and varies according to the region [1-5]. Currently, SL has been recognized in more than 30 countries [5].

Deaf people have particularities in the way they interact with the rest of society, mainly due to differences in the communication aspects [6-8]. Furthermore, a large number of them are illiterate due to educational barriers [1,9]. This communication gap represents a great barrier in healthcare centers, diminishing the quality of healthcare delivered to this population [10-12]. One reason for this situation is that health professionals have limited competencies to meet the specific needs of this population, which results in user dissatisfaction, access barriers, and communication problems [6,13-15].

Many of the obstacles faced by Deaf population are determined by the attitudes of the rest of society. Negative attitudes are a barrier to the inclusion and personal development of Deaf population [16]. Deaf people feel proud of themselves and their culture, and unfavorable attitudes from the hearing society have been reported, such as pity towards Deaf people [17-21].

As attitudes towards Deaf people are structurally different from the rest of the Persons with Disabilities (PwD) [22], in 2004, an instrument was created and validated to specifically measure the attitude of health professionals towards Deafness: The Attitudes Towards Deaf People Scale (ADS) [23], which was recently validated in Chilean population [24]. Until now, there are no reports on Attitudes Towards Deaf People using validated instruments in Latin-American region. This situation is especially problematic for healthcare services because it makes it very difficult for any improvement in the healthcare delivered to Deaf people. Thus it is necessary to assess these attitudes to plan and carry out relevant strategies to improve healthcare for the Deaf community.

This study aimed to assess the attitudes of health professionals towards Deafness in Concepcion, Chile, and its association with sociodemographics and Deaf contact experiences.

\section{Material and Methods}

Study Design and Population

A cross-sectional study was carried out. The target population was health professionals from the province of Concepción. The sample was obtained by convenience from: a) academics from the University of Concepción (UdeC); and b) personnel from public primary healthcare centers (PHC). Primary healthcare staff who do not perform clinical duties and foreign professionals or native speakers of a language other than Spanish were excluded. Sample size was estimated using data reported previously [23] where the ADS mean score for women group was $88.4 \pm 12.1$ points, women have the largest standard deviation; thus, that value allows to estimate a greater sample size with a more precise score. Using that data, a margin of error of 3 points, a power of 0.90 and a level of confidence of 0.95 was chosen, thus the sample size was estimated in 171 participants according to sample size estimations for means module in Stata/SE 12 (Stata Corp., USA).

Variables 
All data were obtained by self-report. The following groups of variables were considered: 1) Sociodemographic: sex (male/female); age (years); years of service in PHC and/or UdeC (years); 2) Deaf contact experience: Do you know someone with hearing impairment? (No/Acquaintance/Friend/Distant relative/Close relative); Do you have training on Deafness? (No/Course/Diploma course/Specialty/Master/PhD); Have you taken a Sign Language Course? (No, One/More than one); Have you delivered healthcare to Deaf patients? (Never/Once/Occasionally/Regularly); 3) Attitudes to Deafness Scale: Using the ADS scale.

The ADS is originally composed of 22 items scored using a Likert scale of 1 to 6 points [23]. After the instrument is applied, the answers are rated 1-6 or 6-1, depending on whether the statement reflects a positive or negative attitude. A score of 6 indicates the most positive response to the affirmation and a score of 1 indicates the most negative response. This instrument has shown adequate psychometric properties with a Cronbach's alpha of 0.71. The Chilean version of the ADS is composed of 11 items, grouped in 4 dimensions: Oralism, Awkward interaction, Social acceptance and Vision of disability (Table 1). It has a Cronbach's alpha of 0.70. The application of the instrument takes around 8 minutes [24].

Table 1. ADS SCALE - Dimensions.

\begin{tabular}{ll}
\hline \multicolumn{1}{c}{ Dimensions } & \multicolumn{1}{c}{ Item Scale } \\
\hline D1 - Oralism & Deaf couples should receive genetic counselling to avoid having deaf children. \\
& Deaf children should learn to speak to communicate with hearing parents. \\
& Deaf people should learn speech rather than sign language. \\
& Deaf people should learn to lip read. \\
D2 - Awkward Interaction & Having a deaf colleague would cause problems in the workplace. \\
& Having a deaf friend would be difficult. \\
D3 - Social Acceptance & I would like to have more Deaf friends. \\
& I would like to have more deaf colleagues. \\
& I would like to see more deaf people at the clubs/societies I attend. \\
D4 - Vision of Disability & Deaf people are handicapped. \\
& Deaf people are physiologically impaired. \\
\hline
\end{tabular}

\section{Data Collection}

Data collection was carried out in PHC and in the health schools of UdeC. There was no monetary nor academic compensation associated with participation. All professionals were selected based on availability. For data collection in PHC, the authorization of each PHC Director was requested. Once authorized, between one and two visits were made to each health center, previously agreed with its director. For data collection at UdeC, authorization was requested from each Faculty Dean. Once authorized, between one and two visits were made to each program, previously agreed with the Dean.

Each participant was informed of the study's aim and their voluntary participation was obtained through signed informed consent. After receiving informed consent from the participant, they answered the Chilean version of the ADS and filled in sociodemographic data (Appendix 2) anonymously. These were introduced into a mailbox by the participant, ensuring confidentiality.

\section{Statistical Analysis}

For statistical analysis, a researcher tabulated data on an Excel spreadsheet (Microsoft, Redmond, USA). The analysis of the data was performed with the InfoStat v. 2014 software (InfoStat, Córdoba, 
Argentina). Data analysis consisted of (i) Descriptive statistics (frequency tables and summary measures) for the characterization of the sample, and (ii) to evaluate the association between the variables t-test was used for dichotomic variables, and Spearman correlation test for quantitative variables $(\mathrm{p}<0.05)$.

Ethics

This study was approved by the Research and Bioethics Committee of the Universidad de Concepción School of Dentistry (C.I.Y.B. $\mathrm{N}^{\circ} \mathrm{O12/18}$ ) and was conducted in full accordance with the World Medical Association Declaration of Helsinki. All respondents agreed to participate by signing informed consent. The survey was anonymous and the information was used only for this research.

\section{Results}

The sample consisted of 182 health professionals, $136(74.7 \%)$ were females with an age mean of 39 years (23-79). For PHC staff, the mean of years of service was 10.5, and for Academics was 11.5. According to career, the sample included: 64 Dentists, 48 Nurse Technicians, 19 Nurses, 17 physicians, 11 Mid-wives, 7 Nutritionists, 6 Kinesiologists, 6 Psychologists, 2 Chemical-pharmaceutical and 1 Speech therapist. Most professionals do not know any Deaf person, have training on Deafness nor taken a Sign Language course (Table 2).

Table 2. Distribution of professionals' contact with Deafness.

\begin{tabular}{lcc}
\hline \multicolumn{1}{c}{ Variables } & N & $\%$ \\
\hline Do you know someone with hearing impairment? & 69 & 37.9 \\
No & 69 & 37.9 \\
Acquaintance & 12 & 6.6 \\
Distant relative & 5 & 2.7 \\
Friend & 38 & 20.9 \\
Close relative & & \\
Do you have training on Deafness? & 159 & 87.4 \\
No & 21 & 11.5 \\
Course & 2 & 1.1 \\
Diploma & 1 & 0.5 \\
Specialty & 0 & 0.0 \\
Master & 0 & 0.0 \\
PhD & & \\
Have you taken a Sign Language course? & 164 & 90.1 \\
No & 16 & 8.8 \\
One & 2 & 1.1 \\
More than one & & \\
Have you delivered healthcare to Deaf patients? & 32 & 17.6 \\
Never & 81 & 44.5 \\
Once & 55 & 30.2 \\
Occasionally & 14 & 7.7 \\
Regularly & &
\end{tabular}

Globally, professionals have a neutral attitude towards Deafness, as seen in Table 3. No differences were observed in the variables of the attitudes towards Deafness regarding sociodemographic or Deaf contact experience variables, as shown in Table 4 . 
Table 3. Item distribution of the attitudes towards Deaf people scale.

\begin{tabular}{|c|c|c|}
\hline Item Scale & Mean & SD \\
\hline 1. Deaf people should learn to lipread & 2.59 & 1.51 \\
\hline 2. I would like to have more Deaf colleagues & 2.94 & 1.54 \\
\hline 3. I would like to have more Deaf friends & 3.44 & 1.49 \\
\hline 4. Deaf children should learn to speak to communicate with hearing parents & 3.57 & 1.98 \\
\hline 5. Deaf people are handicapped & 3.88 & 1.89 \\
\hline 6. I would like to see more Deaf people at the clubs/societies I attend & 4.15 & 1.59 \\
\hline 7. Deaf couples should receive genetic counselling to avoid having deaf children & 4.16 & 1.93 \\
\hline 8. Having a Deaf friend would be difficult & 4.30 & 1.52 \\
\hline 9. Deaf people are physiologically impaired & 4.51 & 1.64 \\
\hline 10. Deaf people should learn speech rather than sign language & 4.58 & 1.60 \\
\hline 11. Having a deaf colleague would cause problems in the workplace & 4.94 & 1.44 \\
\hline Global Mean & 3.92 & 0.82 \\
\hline
\end{tabular}

Table 4. Global mean of professionals' attitudes regarding contact with Deafness.

\begin{tabular}{lccc}
\hline \multicolumn{1}{c}{ Variables } & N & Mean & SD \\
\hline Sex & & & \\
$\quad$ Female & 136 & 3.9 & 0.8 \\
$\quad$ Male & 46 & 3.8 & 0.8 \\
Profession & & & \\
$\quad$ Dentist & 64 & 4.0 & 0.8 \\
$\quad$ Nurse & 19 & 4.1 & 0.7 \\
$\quad$ Speech Therapist & 1 & 4.9 & 0.0 \\
$\quad$ Kinesiologist & 6 & 3.6 & 0.5 \\
$\quad$ Mid-wife & 11 & 3.9 & 1.1 \\
$\quad$ Physician & 17 & 3.9 & 0.6 \\
$\quad$ Nutritionist & 7 & 3.9 & 1.0 \\
$\quad$ Psychologist & 6 & 4.7 & 0.5 \\
$\quad$ Chemical-pharmaceutical & 2 & 2.8 & 0.6 \\
$\quad$ Nurse Technician & 48 & 3.7 & 0.8 \\
Do you know someone with hearing impairment? & & & \\
$\quad$ No & 69 & 4.0 & 0.7 \\
$\quad$ Yes & 113 & 3.8 & 0.8 \\
Do you have training on Deafness? & & & \\
$\quad$ No & 159 & 3.9 & 0.8 \\
$\quad$ Yes & 23 & 4.1 & 0.7 \\
Have you taken a Sign Language course? & & & \\
$\quad$ No & 164 & 3.9 & 0.8 \\
$\quad$ Yes & 18 & 4.1 & 0.7 \\
Have you delivered healthcare to Deaf patients? & & & \\
$\quad$ No & 32 & 3.9 & 0.8 \\
$\quad$ Yes & 3.9 & 0.8 \\
\hline
\end{tabular}

People who had taken a LSCh course had significantly more positive attitudes towards item 1 "Deaf people should learn to lipread", with a 2 points difference and in persons who do not know a Deaf person, with 1point difference. Also, persons who have received some kind of formation in Deafness, have a better attitude in item 3 "I would like to have more Deaffriends" with 1-point difference.

An inverse correlation was observed within age ( $\mathrm{rho}=-0.237 ; \mathrm{p}=0.0014)$, years of academic service $($ rho $=-0.323 ; \mathrm{p}<0.0001)$ or PHC service $(\mathrm{rho}=-0.1085 ; \mathrm{p}=0,364)$. Specifically, item 1 "I would like to have more Deaf colleagues" with years of service, Item 2 "Deaf people should learn to lipread" was correlated with years of 
service, item 3 "I would like to have more Deaffriends" was strongly correlated with academics and item 5 "Deaf people are handicapped' higher with age, years of academic or PHC service.

\section{Discussion}

According to the results, health professionals have a neutral attitude towards Deafness. Nevertheless, in other studies, it has already been observed that people tend to give socially correct answers in explicit instruments [25]. Furthermore, indirect measurement tools, such as Implicit Association Tests, have described negative attitudes towards $\mathrm{PwD}$ [26,27]. Furthermore, Implicit Association Test's results are weakly correlated to the affective, cognitive, and behavioral components of explicit attitudes scales [28]. In addition, many participants expressed difficulties, doubts and discomfort when answering the DAS, and since they feared their responses might be associated with possible discrimination or ignorance about the questions, they chose to respond with neutral attitudes. This feeling of discomfort regarding Deafness was reported by Ralston, where physicians reported feeling less comfortable with Deaf patients and that they are harder to communicate with [2 1$]$

A small proportion of health professionals with training in Deafness was identified, although over $80 \%$ of them have provided healthcare to a Deaf patient. These results agree with previous reports, where most health professionals did not have training in Deafness neither felt they had the skills needed to communicate with a Deaf patient [29,30]. In addition, only 17 participants have taken a SL course; this result agree with the previously reported, where $2.3 \%$ of the nurses have attended a SL course [30]. Most PwD experienced severe health disparities, which could be decreased by providing appropriate training to health professionals [31,32]. Such training should improve the healthcare provided to PwD by modifying some of the factors associated with health professionals' knowledge, attitudes and skills.

Strikingly, there were no significant differences in attitudes among professionals who have completed a LS course and those who did not reveal that these courses are characterized only by teaching a form of communication, leaving aside information about the culture and Deaf people's community. Also, no differences were observed in the attitude by sex, this differs with literature where women have more positive attitudes towards PwD [33,34].

According to current studies, age and PHC employment years have an inverse correlation with DAS $[35,36]$. This was confirmed in our results. It is worth to mention that the items related to the Oralism dimension had the strongest correlation with negative attitudes. This dimension is characterized by focusing on the development of oral language, where the Deaf person must learn to speak and/or adapt to the hearing society, ruling out the use of SL [1,37] This is a worrying situation, as the Chilean Law on Disability recognized the Sign Language as the natural means of communication for the Deaf community [2,38] However, SL access have not been implemented in healthcare services in Chile [2].

We must keep in mind that Deaf population do not want to be normalized nor avoid oral communication. They want a bilingual education, where SL is recognized as primary and oral/written language as a second one. Bilingual education has been recognized as a human right of Deaf children by the World Federation of the Deaf, as it is the only way for Deaf children to gain equal opportunities and become full citizens in their own right [39].

No relevant differences were observed in case of training in Deafness, knowledge of a Deaf person or previous healthcare delivery to a Deaf person. However, the literature showed that receiving training in 
Deafness fostered a positive reaction towards Deaf persons and that the more a participant comes into contact with PwD, the better is their attitude to them, regardless of their disability [36,40].

Implementing a mandatory course on Deaf Culture and Sign Language basics within university education is suggested, thus facilitating future care and eliminating barriers to care for Deaf patients [2,41,42]. Consequently, we must remember that according to the Convention on the Rights of Persons with Disabilities, Deaf people have the same rights as the rest of the population, which includes access to health [43].

Among the limitations of the study, a great proportion of health professionals declined to participate. Also, an unequal distribution among professionals did not allow comparisons between these groups, as most academics where from the School of Dentistry. Thus, these results should be interpreted with caution, and new assessments with greater and more representative samples should be carried out.

\section{Conclusion}

The attitude of health professionals towards Deafness was neutral. This attitude is not modulated by sex, type of profession, type of relationship with Deaf people, type of training in hearing disability, Chilean Sign Language Courses or degree of frequency of healthcare delivery to Deaf patients. However, it is modulated by age and years of service.

\section{Authors' Contributions}

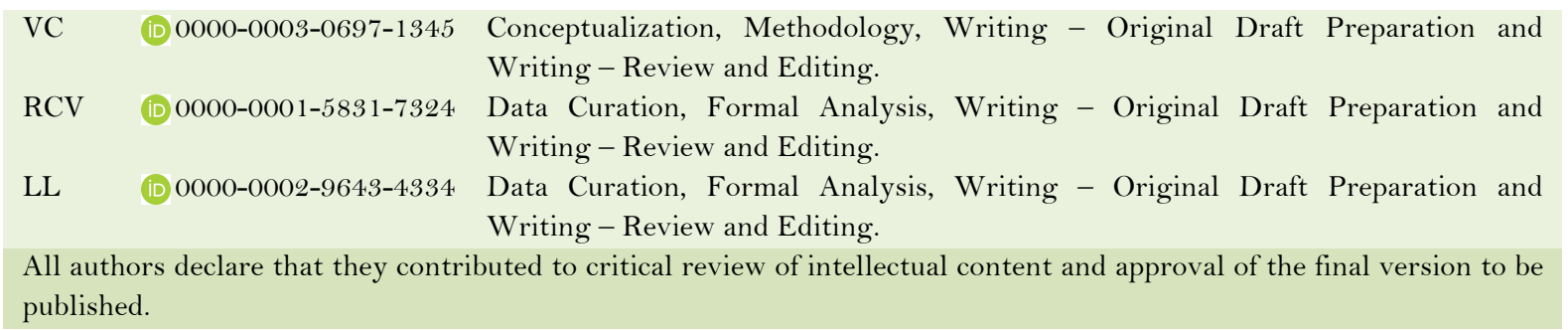

\section{Financial Support}

None.

\section{Conflict of Interest}

The authors declare no conflicts of interest.

\section{Acknowledgements}

John Rose, PhD Director Foren Clin PsyD \& Academic Director ClinPsyD Consultant Clinical Psychologist, St Andrews Heath Care, School of Psychology, University of Birmingham, UK: For his support to validate the Attitudes to Deafness Scale to Spanish. James Orford, PhD Emeritus Professor of Clinical \& Community Psychology, School of Psychology, University of Birmingham, UK: For translation of the instrument.

\section{References}

[1] Ladd P. Deaf Culture: In Search of Deafhood. Clevedon, England: Multilingual Matters Ltd.; 2003.

[2] Campos V. Barriers deaf patients face when receiving dental treatment. J Oral Res 2016; 5(4):144-5. https://doi.org/10.17126/joralres.2016.03

[3] Padden C, Humphries T. Inside Deaf Culture. Cambridge: Harvard University Press; 2005.

[4] Humphries T, Humphries J. Deaf in the time of the cochlea. J Deaf Stud Deaf Educ 2010; 16(2):153-63. https://doi.org/10.1093/deafed/enq054 
[5] De Meulder M. The legal recognition of sign languages. Sign Lang Stud 2015; 15(4):498-506. https://doi.org/10.1353/sls.2015.0018

[6] Kuenburg A, Fellinger P, Fellinger J. Health care access among deaf people. J Deaf Stud Deaf Educ 2016; 21(1):1-10. https://doi.org/10.1093/deafed/env042

[7] Merten JW, Pomeranz JL, King JL, Moorhouse M, Wynn RD. Barriers to cancer screening for people with disabilities: a literature review. Disabil Health J 2015; 8(1):9-16. https://doi.org/10.1016/j.dhjo.2014.06.004

[8] Emond A, Ridd M, Sutherland H, Allsop L, Alexander A, Kyle J. Access to primary care affects the health of Deaf people. Br J Gen Pract 2015; 65(631):95-6. https://doi.org/10.3399/bjgp15X683629

[9] Rezaei M, Rashedi V, Morasae EK. Reading skills in Persian deaf children with cochlear implants and hearing aids. Int J Pediatr Otorhinolaryngol 2016; 89:1-5. https://doi.org/10.1016/j.ijporl.2016.07.010

[10] Bainbridge KE, Wallhagen MI. Hearing loss in an aging American population: extent, impact, and management. Annu Rev Public Health 2014; 35:139-52. https://doi.org/10.1146/annurev-publhealth-032013-182510

[11] Barajas C, González-Cuenca AM, Carrero F. Comprehension of texts by deaf elementary school students: the role of grammatical understanding. Res Dev Disabil 2016; 59:8-23. https://doi.org/10.1016/j.ridd.2016.07.00

[12] McKee MM, Paasche-Orlow MK, Winters PC, Fiscella K, Zazove P, Sen A, et al. Assessing health literacy in Deaf American Sign Language users. J Health Commun 2015; 20(2):92-100. https://doi.org/10.1080/10810730.2015.1066468

[13] Genther DJ, Frick KD, Chen D, Betz J, Lin FR. Association of hearing loss with hospitalization and burden of disease in older adults. JAMA 2013; 309(22). https://doi.org/10.1001/jama.2013.5912

[14] Barnett S, McKee M, Smith SR, Pearson TA. Deaf sign language users, health inequities, and public health: opportunity for social justice. Prev Chronic Dis 2011; 8(2):A45.

[15] Steinberg AG, Barnett S, Meador HE, Wiggins EA, Zazove P. Health care system accessibility: experiences and perceptions of Deaf people. J Gen Intern Med 2006; 21(3):260-6. https://doi.org/10.1111/j.1525-1497.2006.00340.x

[16] Stone DL, Colella A. A model of factors affecting the treatment of disabled individuals in organizations. Acad Manag Rev 1996; 21(2):352-401. https://doi.org/10.2307/258666

[17] Hindley P, Kitson N. Mental Health and Deafness. London: Whurr Publishers; 2000

[18] ChongMin L, Pott SA. University students' attitudes towards deaf people: educational implications for the future. Deafness Educ Int 2018;20(2):80-99. https://doi.org/10.1080/14643154.2018.1438777

[19] Soares RC, Henriques CCB, Araújo ME. Societal attitudes towards the deaf: assessing strategies for their inclusion. Int Arch Otorhinolaryngol 2013; 17(Suppl.):80.

[20] Lee HS, Jung HI, Kim SM, Kim J, Doh RM, Lee JH. Attitudes of Korean dental students toward individuals with special health care needs. J Dent Educ 2015; 79(9):1024-30.

[21] Ralston E, Zazove P, Gorenflo DW. Physicians' attitudes and beliefs about deaf patients. J Am Board Fam Pract 1996; 9(3):167-73. https://doi.org/10.3122/jabfm.9.3.167

[22] Kiger G. The structure of attitudes toward persons who are deaf: emotions, values, and stereotypes. J Psychol 1997; 131(5):554-60. https://doi.org/10.1080/00223989709603544

[23] Cooper A, Rose J, Mason O. Measuring the attitudes of human service professionals toward Deafness. Am Ann Deaf 2004; 148(5):385-89. https://doi.org/10.1353/aad.2004.0001

[24] Belmar N, Quappe I, Luengo L, Campos V. Exploratory Factor Analysis of the Chilean Deafness Attitude Scale. Int J Med Surg Sci 2018; 5(2):80-8. https://doi.org/10.32457/ijmss.2018.020

[25] Feinberg LB. Social desirability and attitudes toward the disabled. Pers Guid J 1967; 46:375-81. https://doi.org/10.1002/j.2164-4918.1967.tb03199.x

[26] Lane KA, Banaji MR, Nosek BA, Greenwald AG. Understanding and using the Implicit Association Test: IV. What we know (so far) about the method. In: Wittenbrink B, Schwarz N. Implicit Measures of Attitudes. New York: Guilford Press; 2006. pp. 59-102.

[27] Pruett SR, Chan F. The development and psychometric validation of the Disability Attitude Implicit Association Test. Rehabil Psychol 2006; 51(3):202-13. https://doi.org/10.1037/0090-5550.51.3.202

[28] Hein S, Grumm M, Fingerle M. Is contact with people with disabilities a guarantee for positive implicit and explicit attitudes? Eur J Spec Needs Educ 201 1; 26(4):509-22. https://doi.org/10.1080/08856257.2011.597192

[29] Vanegas B, Castro L, Páez M, Ramírez N. Comunicación del profesional de enfermería con pacientes que tienen dificultad en la expresión verbal por sordera. Rev Colomb Enferm 2008; 3(3):13-20. [In Spanish]

[30] Velonaki VS, Kampouroglou G, Velonaki M, Dimakopoulou K, Sourtzi P, Kalokerinou A. Nurses' knowledge, attitudes and behavior toward Deaf patients. Disabil Health J 2015; 8(1):109-17. https://doi.org/10.1016/j.dhjo.2014.08.005

[31] World Health Organization. The World Bank. World Report on Disability. Malta: WHO; 2011.

[32] Robey KL, Minihan PM, Long-Bellil LM, Hahn JE, Reiss JG, Eddey GE, et al. Teaching health care students about disability within a cultural competency context. Disabil Health J 2013; 6(4):271-9. https://doi.org/10.1016/j.dhjo.2013.05.002 
[33] Matera C, Dalla Verde S, Meringolo P. I like you more if I think you like me: the effect of metastereotypes on attitudes toward people with Deafness. J Soc Psychol 2015; 155(4):381-94. https://doi.org/10.1080/00224545.2015.1018857

[34] Patka M, Keys CB, Henry DB, McDonald KE. Attitudes of Pakistani community members and staff toward people with intellectual disability. Am J Intellect Dev Disabil 2013; 118(1):32-43. https://doi.org/10.1352/1944-7558-118.1.32

[35] Morin D, Rivard M, Crocker AG, Boursier CP, Caron J. Public attitudes towards intellectual disability: a multidimensional perspective. J Intellect Disabil Res 2013; 57(3):279-92. https://doi.org/10.1111/jir.12008

[36] Cooper AE, Rose J, Mason O. Mental health professionals' attitudes towards people who are deaf. J Community Appl Soc Psychol 2003; 13(4):314-9. https://doi.org/10.1002/casp.725

[37] LissI MR, Svartholm K, González M. El Enfoque bilingüe en la educación de Sordos: sus implicancias para la enseñanza y aprendizaje de la lengua escrita. Est Pedag 2012; 38(2):299-320. [In Spanish]

[38] Chile. Ministerio de Desarrollo Social. II Estudio Nacional de la Discapacidad en Chile. Avalilable from: https://www.senadis.gob.cl/pag/355/1197/ii_estudio_nacional_de_discapacidad. [Accessed on November 8, 2019]. [In Spanish]

[39] World Federation of the Deaf. Bilingualism as a basic human right for deaf children in education. Avalilable from: http://wfdeaf.org/news/bilingualism-as-a-basic-human-right-for-deaf-children-in-education/. _ [Accessed on November 10, 2011].

[40] De Laat S, Freriksen E, Vervloed MP. Attitudes of children and adolescents toward persons who are deaf, blind, paralyzed or intellectually disabled. Res Dev Disabil 2013; 34(2):855-63. https://doi.org/10.1016/j.ridd.2012.1 1.004

[41] Campos V, Cartes-Velásquez R. Estado actual de la atención sanitaria de personas con discapacidad auditiva y visual: Una revisión breve. Rev Méd Chile 2019; 147(5):634-42. [In Spanish]

[42] Campos V, Cartes-Velásquez R, Bancalari C. Development of an app for the dental care of Deaf people: Odontoseñas. Universal Access in the Information Society (2018):1-9. https://doi.org/10.1007/s10209-018-0637-1

[43] United Nations. United Nations Human Rights Office of the High Commissioner. The Convention on the Rights of Persons with Disabilities. New York and Geneva: United Nations Publication; 2014. 